\title{
Comment on: Tseng C-H, Tseng C-P, Chong C-K et al (2006) Increasing incidence of diagnosed type 2 diabetes in Taiwan: analysis of data from a national cohort. Diabetologia 49:1755-1760
}

\author{
T. H.-H. Chen • B. J. Boucher
}

Received: 5 September 2006 / Accepted: 8 September 2006 / Published online: 27 October 2006

(C) Springer-Verlag 2006

To the Editor: The increasing trend in the incidence of diagnosed type 2 diabetes reported in Diabetologia by Tseng and colleagues [1] parallels increases in obesity. Both are matters for concern and, no doubt, associated with other markers of increasing affluence. The authors state that 'there is an urgent need to take early action to halt this trend... especially in the young generation, in whom obesity is a potential target of intervention.' We have reported independent dose effects for the associations of betel chewing in Keelung City with increases in the prevalence of both type 2 diabetes and the metabolic syndrome, as well as each of the five features used in the diagnosis of the metabolic syndrome, including central obesity [2]. We calculated meaningful risk ratios of 1.41 (95\% CI 1.18 1.68) for type 2 diabetes and 1.78 (95\% CI 1.53-2.08) for the presence of the metabolic syndrome according to the National Cholesterol Education Programme, Adult Treatment Panel III criteria [2] modified for Asian individuals [3, 4]. These associations were found in men but not in women, since too few women in Keelung City were betel

\footnotetext{
T. H.-H. Chen $(\bowtie)$

Institute of Preventive Medicine, College of Public Health,

National Taiwan University,

Room 207, 19 Hsuchow Road,

Taipei 100, Taiwan

e-mail: stony@episerv.cph.ntu.edu.tw

\section{B. J. Boucher}

Centre for Diabetes and Metabolic Medicine,

Institute for Cellular and Molecular Science,

Queen Mary School of Medicine and Dentistry,

University of London,

London, UK
}

chewers to permit analyses. We also found reductions in these risks with duration since cessation of betel chewing. Our findings suggest that cessation of betel chewing could lead to a meaningful reduction in the risk of developing obesity and type 2 diabetes, in men if not in women. It is likely that a similar association would be found in the population studied by Tseng et al. [1], since the incidence of type 2 diabetes was higher among men than women and, according to our data [3], among men, betel chewers are younger than non-chewers. If associations are found, cessation of betel chewing would be an additional target for intervention for reduction in the problems of obesity and type 2 diabetes, as well as in cancer prevention [5].

\section{References}

1. Tseng C-H, Tseng C-P, Chong C-K et al (2006) Increasing incidence of diagnosed type 2 diabetes in Taiwan: analysis of data from a national cohort. Diabetologia 49:1755-1760

2. Expert Panel on Detection, Evaluation, and Treatment of High Blood Cholesterol in Adults (2001) Executive summary of the third report of the National Cholesterol Education Program (NCEP) expert panel on detection, evaluation, and treatment of high blood cholesterol in adults (Adult Treatment Panel III). JAMA 285: 2486-2497

3. Tung T-H, Chiu Y-H, Chen L-S, Wu H-M, Boucher BJ, Chen T H-H (2004) A population-based study of the association between areca nut chewing and type 2 diabetes mellitus in men (Keelung Communitybased Integrated Screening programme no. 2). Diabetologia 47:1776-1781

4. Yen A M-F, Chiu Y-H, Chen L-S, Wu H-M, Huang C-C, Boucher BJ, Chen T H-H (2006) A population-based study of the association between betel-quid chewing and the metabolic syndrome in men. Am J Clin Nutr 83:1153-1160

5 International Agency for Research on Cancer (2004) IARC monographs on the evaluation of carcinogenic risks to humans, vol 85. In: Betel-quid and areca-nut chewing and some areca-nutderived nitrosamines. IARC, Lyon 